\title{
Intratemporal Facial Nerve Paralysis- A Three Year Study
}

\author{
Anirban Ghosh, ${ }^{1}$ Sankar Prasad Bera, ${ }^{2}$ Somnath Saha ${ }^{3}$
}

Introduction

\section{ABSTRACT}

This study on intratemporal facial paralysis is an attempt to understand the aetiology of facial nerve paralysis, effect of different management protocols and the outcome after long-term follow-up.

\section{Materials and Methods}

A prospective longitudinal study was conducted from September 2005 to August 2008 at the Department of Otorhinolaryngology of a medical college in Kolkata comprising 50 patients of intratemporal facial palsy. All cases were periodically followed up for at least 6 months and their prognostic outcome along with different treatment options were analyzed.

\section{$\underline{\text { Result }}$}

Among different causes of facial palsy, Bell's palsy is the commonest cause; whereas cholesteatoma and granulation were common findings in otogenic facial palsy. Traumatic facial palsies were exclusively due to longitudinal fracture of temporal bone running through geniculate ganglion. Herpes zoster oticus and neoplasia related facial palsies had significantly poorer outcome.

\section{Discussion}

Otogenic facial palsy showed excellent outcome after mastoid exploration and facial decompression. Transcanal decompression was performed in traumatic facial palsies showing inadequate recovery. Complete removal of cholesteatoma over dehiscent facial nerve gave better postoperative recovery.

\section{Conclusion}

The stapedial reflex test is the most objective and reproducible of all topodiagnostic tests. Return of the stapedial reflex within 3 weeks of injury indicates good prognosis. Bell's palsy responded well to conservative measures. All traumatic facial palsies were due to longitudinal fracture and $2 / 3 \mathrm{rd}$ of these patients showed favourable outcome with medical therapy.

Keywords:

Facial Paralysis; Bell Palsy; Herpes Zoster Oticus; Facial Nerve Injuries; Cholesteatoma; Decompression, Surgical; Treatment Outcome

$\mathrm{F}$ acial nerve, more than any other cranial nerves, affects non-verbal humanistic expression, which is a significant component of communication. Facial nerve, originates from the pons, emerges through cerebello-pontine angle, and runs a long intratemporal course and exits through stylomastoid foramen to supply different muscles of facial expression. This long intra-osseous part of the nerve makes it vulnerable to different types of injuries ranging from local oedema

1 - Hope Nursing Home, Raniganj, West Bengal

2 - Department of ENT, KPC Medical College, Kolkata

3- Department of ENT, NRS Medical College, Kolkata

\section{Corresponding author:}

Dr Anirban Ghosh

email: way2anirban@gmail.com to entrapment of the nerve in the bony canal or even impingement of the nerve by bony spicule after fracture of temporal bone.

Treatment of facial palsy is individualized depending on cause, duration, degree of facial palsy.

Intratemporal facial paralysis and its treatment outcome have been studied in other parts of the world, but a proper study in eastern India is lacking. This study is an attempt to understand the aetiology of facial nerve paralysis, effect of different management protocols and the outcome after long-term follow-up.

\section{Materials and Methods}

This prospective longitudinal study was conducted at a 
medical college in Kolkata on fifty consecutive patients of intratemporal facial palsy, who presented to the Department of Otorhinolaryngology during a three year period from September 2005 to August 2008.

Facial palsy due to parotid surgery and upper motor type facial palsy were excluded.

After detailed history taking all patients underwent thorough general and routine otorhinolaryngological examination. Facial nerve palsy was graded according to House-Brackman grading system. Topodiagnostic tests and Electro-Myography, Pure Tone Audiometry and tympanometry were performed in all patients. Topodiagnostic tests included Schirmer's test for lacrimation, Stapedial reflex, Taste sensation from anterior two-third of tongue.

HRCT scanning of temporal bone was the radiological investigation of choice in this study. Treatment of all patients presented with facial nerve palsy was individualized depending on the aetiology, duration and degree of facial palsy.

\section{Results}

Age and sex distribution of the study group shows most of the patient belongs to the 10-20 year age group (30\%) with a male: female ratio of $2.75: 1$.

Most common cause of facial nerve paralysis in our study was found to be Bell's palsy (50\%). Among different types of otitis media that causes facial nerve paralysis, squamosal disease was found in $75 \%$ (3/4 patients). Traumatic facial palsy including iatrogenic palsy, herpes infection and neoplasm are other important causes of facial palsy. (Table I)

Pre-operative audiological profile of these patients showed 2 patients had mixed hearing loss; rest of the patients had conductive type of hearing loss with most of them showed mild conductive loss.

Topodiagnostic tests are done to locate the site of injury of the facial nerve before any intervention. 10 patients showed bizarre results of topodiagnostic tests.

In electromyography, patients with grade VI or grade $\mathrm{V}$ facial weakness showed acute denervation pattern whereas grade IV and grade III facial palsy patients had
Table I : Comparison of different aetiologies of facial palsy between present study and another study

\begin{tabular}{|c|c|c|}
\hline & & \\
\hline & & \\
\hline BETIOLOGY & $51 \%$ & $50 \%$ \\
\hline Otitis media & $4 \%$ & $8 \%$ \\
\hline Traumatic & $22 \%$ & $24 \%$ \\
\hline Herpes zoster oticus & $7 \%$ & $6 \%$ \\
\hline $\begin{array}{c}\text { Neoplasms } \\
\text { Syndrome, Necrotising otitis } \\
\text { externa, TB, HIV) }\end{array}$ & $\mathbf{8 . 5 \%}$ & $\mathbf{8 \%}$ \\
\hline
\end{tabular}

partial denervation pattern.

Bells's palsy was treated with short course high dose corticosteroid (1mg/kg/day), antiviral, facial exercise in 20/25 patients. The rest 5 patients of Bell's palsy were observed without any medication. Facial palsy due to squamosal disease was essentially treated with insideout mastoidectomy. It was observed that, cholesteatoma mostly compressed the dehiscent facial nerve and granulation tissue intermingled with facial nerve. The single case of facial palsy due to acute otitis media was treated with myringotomy and intravenous antibiotic therapy with steroids. Traumatic facial palsy was noticed in longitudinal fracture. Transcanal decompression was performed in those cases showing inadequate recovery (patients with more than Grade III facial palsy after 3 months of optimal medical treatment). In transcanal facial decompression, first canalplasty was performed, then atticotomy, incus and head of malleus were removed to gain access to horizontal part of facial nerve. Drilling out of processus cochleariformis is essential to decompress inferior part of geniculate ganglion. After decompression malleostapedopexy was done by rotating the malleus laterally (by cutting the tensor tympani tendon).

All patients of Bell's palsy who were treated showed 
favourable outcome (grade I/II), whereas $75 \%$ cases of observation group showed good outcome. Two cases of Bell's palsy had multiple $(>1)$ episodes of facial palsy but showed favourable results. Otogenic facial palsy showed excellent outcome after mastoid exploration and facial decompression. But cases with long duration ( $>1$ year), complete transection with loss of significant amount of nerve tissue showed poorer outcome even after nerve grafting. Complete removal of cholesteatoma over dehiscent facial nerve was usually enough to give better outcome. Transcanal decompression of traumatic facial palsy showed good results after long term followup (3-6 months after surgery).

\section{Discussion}

Facial nerve is more prone to injury than any other cranial nerve due to its long intratemporal course. A review of medical literature from 1900 to1990 has revealed a host of condition that can cause facial nerve paralysis. Most of these conditions also were represented among the presenting diagnoses for 2856 patients who had facial paralysis seen by Mark May ${ }^{1}$ between 1963 and June 1990.

Among otologic facial palsy, cholesteatoma was found in $50 \%$ (2/4 patients) cases, whereas granulation tissue was the offending factor in $25 \%$ ( $1 / 4$ patients).

Table II : Comparison of otogenic facial palsy between present study and other studies

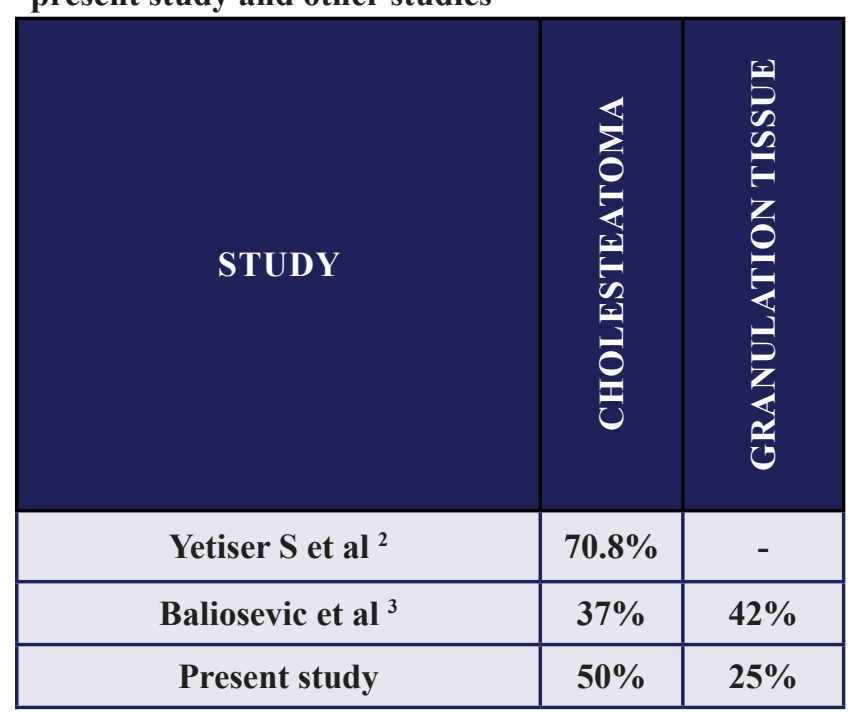

Table III : Comparison of traumatic facial palsy and their site of injury between present study and other studies

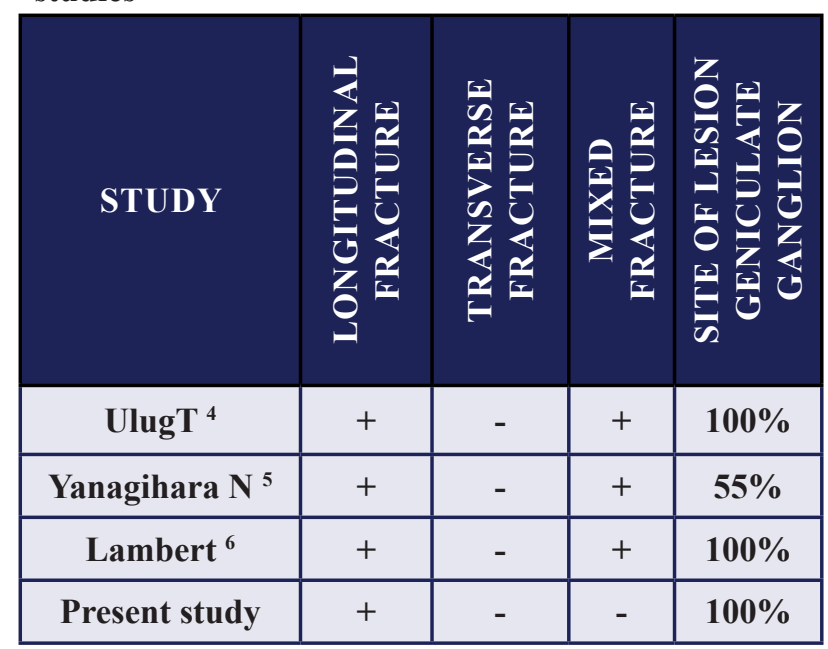

Yetiser $\mathrm{S}$ et $\mathrm{al}^{2}$ found $70.8 \%$ of patients with facial palsy caused by chronic otitis media had cholesteatoma, whereas Baliosevic et $\mathrm{al}^{3}$ found it in only $37 \%$ of cases. (Table II)

Comparison of literature regarding traumatic facial palsy has been noted in Table III.

Mark May ${ }^{1}$ found Herpes zoster oticus in $7 \%$ of cases, whereas it was $6 \%$ in the present study. All had vesicles in the pinna and external auditory canal and face. Mark May ${ }^{1}$ stated that eruptions may be delayed up to ten days after facial palsy.

In this study, we grade facial nerve status by using House-Brackmann grading system. At the University of Iowa, Gidley and colleagues ${ }^{7}$ use 'Repaired Facial Nerve Recovery Scale' (RFNRS), for nerve resections repaired by neurorraphy or grafting. Like the HB scale, the RFNRS has six grades but uses letters instead of numbers (Grade A to F). Topodiagnostic tests have been done in the present series to locate the exact site of lesion. But it was found to produce bizarre results in $40 \%$ of cases. Currently, these tests are used infrequently because of the unreliable information provided. Adour ${ }^{8}$ observed great discrepancy in the results of these tests: marked decrease in lacrimation with normal stapedial reflex and normal taste; or absent lacrimation, absent stapedial reflex with normal taste sensation. Similar findings are also observed in the present series. 
Table IV : Comparison of treatment protocol of Bell's palsy and its outcome between present study and other studies

\begin{tabular}{|c|c|c|c|}
\hline STUDY & 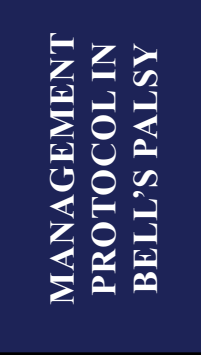 & 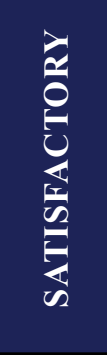 & 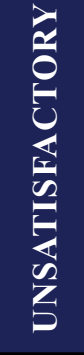 \\
\hline Mark May ${ }^{9}$ & Observation & $84 \%$ & $16 \%$ \\
\hline \multirow[b]{2}{*}{ Present study } & Observation & $75 \%$ & $25 \%$ \\
\hline & $\begin{array}{c}\text { Steroid } \\
+ \text { Facial } \\
\text { exercises }\end{array}$ & $100 \%$ & Nil \\
\hline
\end{tabular}

Of all topodiagnostic tests, the stapedial reflex test is the most objective and reproducible. An absent stapedial reflex that returns to normal within 3 weeks of injury indicates returning of facial function, thus this test has been termed as "otolaryngologist's electromyography" by Adour. ${ }^{8}$

Mark May ${ }^{9}$ found that outcome in patients treated surgically was no better than can be expected to occur without treatment in Bell's palsy. Gantz et al ${ }^{10}$ recommended surgical decompression of the nerve from meatal foramen up to tympanic part through middle cranial fossa approach in patients showing more than $90 \%$ denervation in Electroneuronography (ENoG) and absent motor unit potential within 14 days of onset of Bell's palsy. In this study, we treated patients with serial follow-up and exercises in 5 cases, 20 patients were managed with oral corticosteroids in a dose of $1 \mathrm{mg} / \mathrm{Kg} /$ day Prednisolone and facial exercises. (Table IV)

Patients with $<90 \%$ of degeneration in ENoG and voluntary action potential can be treated with oral steroids and facial exercises, whereas patients with poor prognostic variables are better managed with facial nerve decompression through middle cranial fossa route.

Patients with facial nerve palsy due to chronic otitis media were treated mostly with mastoid exploration and
Table $V$ : Comparison of treatment options of otogenic facial palsy between present study and other studies

\begin{tabular}{|c|c|c|c|}
\hline$\stackrel{\theta}{\frac{\theta}{\theta}}$ & 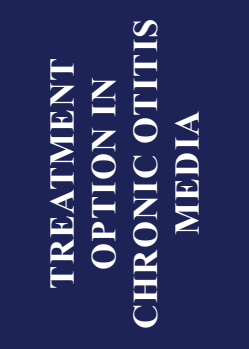 & 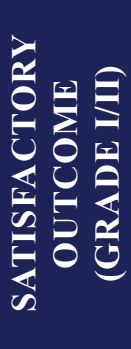 & 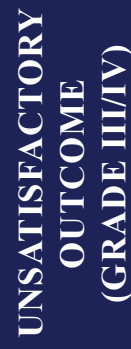 \\
\hline$\phi=$ & Open technique & $75 \%$ & $25 \%$ \\
\hline$\tilde{N} \mathscr{n}$ & Close technique & $66.67 \%$ & $33.33 \%$ \\
\hline 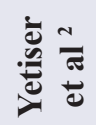 & $\begin{array}{l}\text { CWU \& CWD } \\
\text { mastoidectomy }\end{array}$ & $53.8 \%$ & $46.2 \%$ \\
\hline \multirow{3}{*}{ 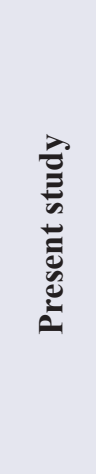 } & $\begin{array}{l}\text { Combined } \\
\text { approach }\end{array}$ & Nil & $100 \%$ \\
\hline & $\begin{array}{c}\text { Modified } \\
\text { radical } \\
\text { mastoidectomy } \\
\text { + FND }\end{array}$ & $80 \%$ & $20 \%$ \\
\hline & $\begin{array}{c}\text { Modified } \\
\text { radical } \\
\text { mastoidectomy } \\
\text { + FN grafting }\end{array}$ & Nil & $100 \%$ \\
\hline
\end{tabular}

facial nerve decompression. (Table V)

All patients with traumatic facial nerve palsy had longitudinal fracture in the temporal bone. Patients with traumatic facial palsy were initially treated with steroids, physiotherapy etc. Patients who showed poorer outcome (Grade III or more) after three months of optimal medical therapy were subjected to transcanal decompression of facial nerve. 4 out of 12 patients had grade V/VI palsy after medical therapy and subjected to transcanal decompression of facial nerve. (Table VI)

Lambert and Brackmann ${ }^{6}$ suggested early exploration of traumatic facial nerve palsies by a combined approach, consisting of both middle cranial fossa and transmastoid approaches. Yanagihara ${ }^{5}$ approached by transmastoid 
supralabyrinthine route. He also proposed this route avoids hazards of craniotomy. In this study, we found that decompression of the nerve in traumatic facial nerve paralysis gives satisfactory results through transcanal route. The single case of iatrogenic facial nerve palsy

Table VI : Comparison of treatment options of traumatic facial palsy between present study and another study

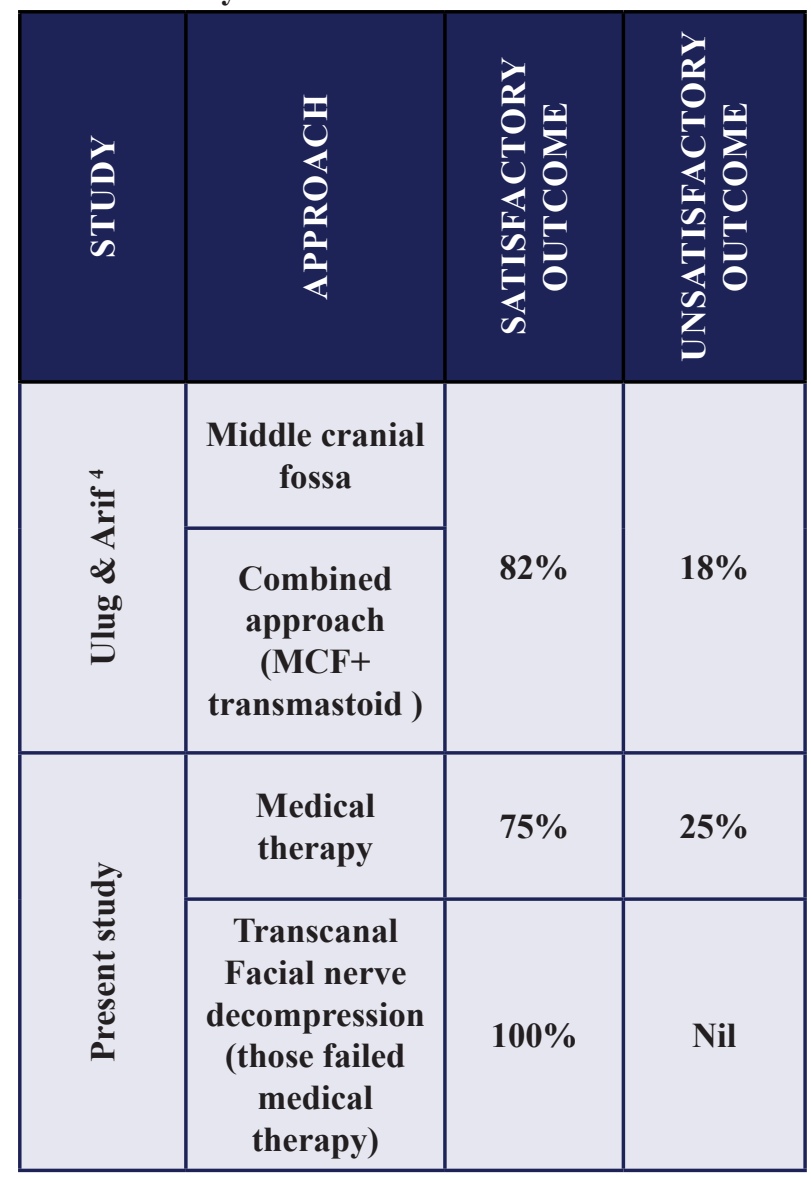

was due to mastoid exploration done outside. The lesion was found to be in the vertical segment of the nerve.

All patients of Ramsay-Hunt syndrome were treated with oral Acyclovir, steroids and facial exercises. One out of 3 patients showed satisfactory outcome, Mark May ${ }^{9}$ postulated $60 \%$ of these patients recover satisfactorily while Fardin ${ }^{12}$ showed $73 \%$ of patients would have poor prognosis with residual paralysis. Dickins ${ }^{13}$ proposed the use of intravenous Acyclovir as the main treatment option for this syndrome.

Among 2 cases (4\%) of neoplasms that caused facial nerve palsy, 1 had squamous cell carcinoma of the tympanomastoid region and 1 had multiple myeloma affecting the intrameatal part of facial nerve along with multiple cranial nerve paralysis.

This study has shown that treatment of facial nerve palsy should be individualized depending on the aetiology, duration, site of lesion etc. Though surgical treatment had shown good outcome, statistical significance could not be calculated due to small number of study population. This study is being carried forward to include large number of patients of facial palsy due to different causes to get a statistical significant outcome.

\section{Conclusion}

Bell's palsy was the most common cause of facial palsy in this study and it was mostly treated with medical therapy with favourable outcome. Otogenic facial palsy was commonly due to cholesteatoma and granulation (Squamous type of COM). These patients were treated with modified radical mastoidectomy with facial nerve decompression with good outcome. However facial nerve palsy for long duration, complete neuronal discontinuity requiring nerve grafting usually produce unfavourable outcome. All traumatic facial palsies were due to longitudinal fracture and $2 / 3 \mathrm{rd}$ of these patients showed favourable outcome with medical therapy. Transcanal approach is a tailor-made approach for traumatic facial palsy with good outcome with disadvantage of poor postoperative hearing. Herpes zoster oticus and neoplasms had shown uniformly poor prognosis.

\section{References}

1. May M, Klein SR. Differential diagnosis of facial nerve palsy. Otolaryngol Clin North Am. 1991; 24(3):613-45

2. Yetiser S, Tosun F, Kazakavasi M. Facial nerve paralysis due to chronic otitis media. Otol Neurotol. 2002; 23(4):580-8

3. Baliosevic I, Micic S, Baliosevic Z, Milovanovic J. Facial nerve paralysis as a sequlae of chronic suppurative otitis. Med Pregl. 2000; 53(1-2):93-6

4. Ulug T, Ulubil AS. Management of facial paralysis in temporal bone fractures: a prospective study analyzing 11 operated frac- 
tures. Am J Otolaryngol. 2005; 26(4):230-8

5. Yanagihara N. Transmastoid decompression of the facial nerve in temporal bone fracture. Otolaryngol Head Neck Surg. 1982; 90(5):616-21

6. Lambert PR, Brackmann DE. Facial paralysis in longitudinal temporal bone fractures: a review of 26 cases. Laryngoscope 1984; 94(8):1022-6

7. Gidley PW et al. Facial nerve grafts: from cerebellopontine angle and beyond. Am J Otol. 1999; 20:781-8

8. Adour KK. Medical Management of Idiopathic (Bell's) palsy. Otolaryngol Clin North Am. 1991; 24(3): 663-73

9. May M, Klein SR, Taylor FH. Idiopathic (Bell's) facial palsy: Natural history defies steroid or surgical treatment. Laryngo- scope $1985 ; 95(4): 406-9$

10. Gantz BJ, Rubinstein JT, Gidley P, Woodworth GG. Surgical management of Bell's palsy. Laryngoscope 1999; 109(8):117788

11. Zhang L, Song W. The treatment of facial nerve palsy related to cholesteatoma otitis media. Lin Chuang Er Bi Yan Hou Ke Za Zhi 2002;16(4):158-9

12. Fardin P, Negrin P, Peserico A. EMG prognosis of facial nerve associated with herpes zoster oticus (Ramsay-Hunt's syndrome). A longitudinal study of 11 cases. Riv Patol Nerv Ment. 1977; 98(3): 151-8

13. Dickens JR, Smith JT, Graham SS. Herpes zoster oticus: treatment with intravenous acyclovir. Laryngoscope 1988; 98:776-9 